NBSIR 86-3429

\title{
Transport of Electrons and Associated Bremsstralung Through A Composite Aluminum-Lead Shield, With Applications to Spacecraft Shielding
}

Gideon Barnea, Stephen M. Seltzer and Martin J. Berger

U.S. DEPARTMENT OF COMMERCE

National Bureau of Standards

Center for Radiation Research

Gaithersburg, MD 20899

July 1986

Prepared for:

Office of Health and Environmental Research

Department of Energy

Washington, DC 20545

and

ice of Naval Research

OC ington, Virginia 22217 

TRANSPORT OF ELECTRONS AND

ASSOCIATED BREMSSTRALUNG THROUGH

A COMPOSITE ALUMINUM-LEAD

SHIELD, WITH APPLICATIONS TO

SPACECRAFT SHIELDING

Gideon Barnea, Stephen M. Seltzer and Martin J. Berger

U.S. DEPARTMENT OF COMMERCE

National Bureau of Standards

Center for Radiation Research

Gaithersburg, MD 20899

July 1986

Prepared for:

Office of Health and Environmental Research

Department of Energy

Washington, DC 20545

and

Office of Naval Research

Arlington, Virginia 22217

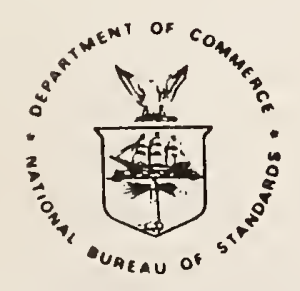

U.S. DEPARTMENT OF COMMERCE, Malcolm Baldrige, Secretary NATIONAL BUREAU OF STANDARDS. Ernest Ambler, Director 

TRANSPORT OF ELECTRONS AND ASSOCIATED BREMSSTRAHLUNG THROUGH A COMPOSITE ALUMINUM-LEAD SHIELD, WITH APPLICATIONS TO SPACECRAFT SHIELDING

\author{
Gideon Barnea, ${ }^{\star *}$ Stephen M. Seltzer and Martin J. Berger \\ Center for Radiation Research \\ National Bureau of Standards \\ Gaithersburg, Maryland 20899
}

\begin{abstract}
Monte Carlo calculations have been made of the stopping of electrons and the penetration of secondary bremsstrahlung through layered aluminum-lead spacecraft walls. The results are presented in terms of the resultant radiation dose to objects inside. Dose values for monoenergetic incident electrons are given as a function of the aluminum/lead thickness ratio. These data, integrated over a few typical Earth-orbit electron spectra, demonstrate the substantial reduction in radiation dose that can be achieved by replacing a portion of an aluminum shield with an inner layer of lead. The main results were obtained by applying a complex-geometry code to spherical-shell configurations. It was found that these results could be reasonably well approximated by an alternative and more economical approach, involving the use of slab-geometry transport results.
\end{abstract}

KEYWORDS: absorbed dose; bremsstrahlung; composite shield; electrons; Monte Carlo calculation; space shielding;

* This work was carried out with support from the Office of Naval Research, and the Department of Energy (Office of Health and Environmental Research).

${ }^{\star *}$ On sabbatical leave from Raphael Laboratories, Haifa, Israel. 



\section{INTRODUCTION}

In a recent paper $[1],{ }^{\dagger}$ we reported on calculations of the penetration of electrons and their bremsstrahlung through spacecraft walls and the resultant radiation dose to objects inside. These calculations were done with a general-geometry, electron/photon transport Monte Carlo code. Results were presented for four incident electron spectra, typical of those that might be encountered in Earth orbit. The present report extends this work in two respects: a) results are given for monoenergetic electron beams, which can be used to obtain results for any incident flux spectrum, and b) some comparisons are made with results from a more-efficient, approximate method of calculation.

The calculations were done for application to the near-Earth radiation environment which contains electrons with kinetic energies less than about $6 \mathrm{MeV}$. We consider an omni-directional flux of electrons incident on spacecraft walls, typically made of aluminum. The mass thicknesses of the wall (shield) assumed here, 3 and $5 \mathrm{~g} / \mathrm{cm}^{2}$, are such that nearly all the incident electrons are stopped in the wall. However, part of the electron energy is converted into bremsstrahlung photons which can penetrate the shield. The efficiency for the conversion of electron energy to bremsstrahlung energy is roughly proportional to the atomic number $Z$ of the medium. Even though this efficiency is relatively low in aluminum, the bremsstrahlung photons may nevertheless constitute a significant radiation hazard. The penetration of this secondary radiation could be reduced by merely increasing the mass thickness of the wall, but this would result in heavier spacecraft. Instead, our calculations were done to determine the extent to which the radiation dose from transmitted bremsstrahlung can be reduced by replacing the aluminum shield with a two-layer aluminum/lead shield, without an increase in the total mass thickness of the shield. In this case, the outer aluminum $(l o w-Z)$ layer serves to slow down the incident electrons, while limiting the production of bremsstrahlung photons to relatively low levels. The inner lead (high-Z) layer then serves to absorb the bremsstrahlung photons as much as possible. For the purpose of this study, we calculate the absorbed dose (energy deposited divided by the mass) in a $40-\mathrm{cm}$ diameter water sphere located inside relatively simple shell structures used to represent the spacecraft.

The primary aim of this work was to develop quantitative information on the ability to reduce the bremsstrahlung dose inside the spacecraft by replacing an inner layer of the aluminum wall with the same mass thickness of lead, assuming a total mass thickness for the wall of either 3 or $5 \mathrm{~g} / \mathrm{cm}^{2}$. For this purpose we used a state-of-the-art computer code which accurately calculates the transport of electrons and bremsstrahlung through matter and which handles the general problem of multi-material, three-dimensional geometries. Such a code requires substantial computing time not only because it must accurately treat the complex radiation transport processes involved, but also because it must handle the complicated geometry. Therefore, a secondary purpose was to see to what accuracy corresponding results obtained in simple slab geometry, using the same transport model, could be applied to these three-dimensional cases, with much less computational effort.

\footnotetext{
Tumbers in brackets indicate the literature references at the end of this document.
} 
The methods of calculation are indicated in section 2. Section 3 gives results of test calculations which indicate the sensitivity of the dose to the shape and inner dimensions of the shield. In section 4, the dose for monoenergetic fluxes of electrons with incident energies of $0.2,0.5,1,2,3,4$, 5 , and $6 \mathrm{MeV}$ is given, as a function of the fraction of the shield mass thickness that is lead, for a total mass thickness of the shield of both 3 and $5 \mathrm{~g} / \mathrm{cm}^{2}$. In section 5 , dose rates are presented in a similar fashion for some typical space missions, obtained by integrating the monoenergetic results over the appropriate orbit-averaged flux spectra. Throughout, we also offer for comparison some corresponding results obtained by transforming simple slab results to apply to the same geometric configuration used in the direct calculations.

\section{METHODS OF CALCULATION}

All calculations were made using codes based on the ETRAN Monte Carlo electron/photon transport model $[2,3]$. This model has previously been used in space-shielding calculations done for simple, uniform slabs $[4,5]$. The model treats in detail the penetration, diffusion and slowing down of the electrons, the production of bremsstrahlung in successive Coulomb collisions, and the further penetration of the secondary brensstrahlung photons. The direct calculations for the three-dimensional, multi-material configurations were done with the ACCEPT code [6], which couples the ETRAN model to a combinatorial geometry program. The use of combinatorial geometry enables ACCEPT to handle quite complicated configurations. The present calculations were restricted to spherical and cylindrical shells, representing the spacecraft walls, surrounding the 40-cin diameter water target sphere.

The calculations in simple, multi-layer slab geometry were done using the ETRAN-based ZTRAN Monte Carlo code [7], a one-dimensional calculation which takes into account only the spatial variable measured normal to the plane boundary interfaces. The transformation of the slab results to the threedimensional case was accomplished using a procedure whose details are given elsewhere [8]. Briefly, this procedure is based on the assumption of (i) a uniform, isotropic flux of radiation incident on a homogeneous target, either a semi-infinite slab or a solid sphere, and ( $i$ ) the existence of a function, applicable to both the slab and the sphere, that describes the energy deposited by the electrons and secondary bremsstrahlung as if the incident radiation penetrates along the direction of incidence. As applied to the yeometry considered here, the energy deposited in the water target sphere is given in terms of an appropriate integral over the depth-dose distribution in a slab composed of the layered shield followed by a thick water layer. The integral is multiplied by a geometric factor which is introduced to take into account the void region that is present in our three-dimensional cases.

\section{DEPENDENCE ON THE SPACECRAFT SHAPE AND INNER DIMENSIONS}

To study the sensitivity of the dose inside the spacecraft to its shape and inner dimensions, several calculations were made for various size spherical and cylindrical shells. In all cases the walls were assumed to be $1 \mathrm{~cm}\left(2.7 \mathrm{~g} / \mathrm{cm}^{2}\right)$ thick aluminum, irradiated by $2-\mathrm{MeV}$ electrons. In the Monte Carlo calculations, cut-off energies (below which histories are no longer followed) were chosen to be $0.1 \mathrm{MeV}$ for electrons and $0.01 \mathrm{MeV}$ for photons. 
Table 1 gives the directly-calculated energy deposition (normalized to an incident fluence of one electron per $\mathrm{cm}^{2}$ ) in the $40-\mathrm{cm}$ diameter water sphere located at the center of the shell. The results indicate that the dose is rather insensitive to the shape and inner dimensions of the she11: a change of nearly an order in magnitude in the inner dimensions causes a change of less than 10 percent in the dose. Such a finding tends to confirm the expectation that the isotropic flux of electrons incident on the outside surface of the uniformly-thick shell produces a flux of bremsstrahlung photons emerging from the inside surface of the shell that is effectively isotropic, so that the $1 / r^{2}$ decrease in the dose at the center of the shell is largely compensated for by the increase in the shell surface area as the radius of the shell is made larger. Moreover, if this is the case, one can consider the problem as a detector sphere located in a region of isotropic photon flux, so that the dose is also independent of its position in that region. This was investigated by means of a few calculations which vary the position of the water sphere within a shel1. The results, given in Table 2, indeed show little sensitivity to the position of the water sphere.

The results from the transformation of simple slab results are also given in Table 1, and agree fairly well with those from the direct calculations. The agreement is in good part due to the fact that the high degree of isotropy of the generated photon flux mirrors the isotropy of the incident electron flux, which conforms well with the type of straight-ahead approximation underlying the transformation procedure.

Because the results are relatively independent of the inner dimension of the shell and of the position of the water sphere within, all subsequent calculations were made for a spherical shield with an outer diameter of 1 meter, concentric with the $40-\mathrm{cm}$ water target sphere (see fig. 1 ). This configuration was adopted because it takes into account the realistic case of a void region between the shield and the target, while keeping the Monte Carlo calculation statistically efficient (i.e., making it sufficiently likely that the sampled bremsstrahlung photon trajectories actually traverse the water sphere).

\section{MONOENERGETIC INCIDENT ELECTRONS}

The energy deposited in the water target sphere was calculated for monoenergetic, omni-directional incident electrons as a function of the fraction of the shield mass thickness that is lead. The total mass thickness of the shield was kept constant at $3 \mathrm{~g} / \mathrm{cm}^{2}$ or $5 \mathrm{~g} / \mathrm{cm}^{2}$, and the mass thickness of the outer aluminum layer was varied from the total mass thickness down to $0.1 \mathrm{~g} / \mathrm{cm}^{2}$. Calculations were done for incident electron kinetic energies of $6,5,4,3,2,1,0.5$, and $0.2 \mathrm{MeV}$. Lower incident electron energies were not considered because, for the spectra likely to be encountered in near-Earth orbit, the contribution to the dose by electrons with energies below $0.2 \mathrm{MeV}$ is negligible for our geometry. The cut-off energies were chosen to be either 5 percent of the incident energy or $0.2 \mathrm{MeV}$, whichever was lowest. Each of the ACCEPT calculations was based on a sample of from 5000 to 10000 incident electron histories and on from 125,000 to 250,000 generated bremsstrahiung photon histories. The statistical uncertainty of the calculated energy deposited in the water target sphere is estimated to be 5-10 percent. 
The results of the calculations are given in figures $2 a$ and $b$ for the shield with a total mass thickness of $3 \mathrm{~g} / \mathrm{cm}^{2}$, and in figure 3 for $5 \mathrm{~g} / \mathrm{cm}^{2}$. The small vertical arrows in figures 2 and 3 indicate that fractional mass thickness for which the thickness of the outer aluminum layer is equal to the incident electron range (in the continuous-slowing-down approximation). In most cases, an increase in the fractional mass thickness of the lead layer produces a similar effect. At first there is a gradual decrease in the energy deposited, due to an increase in the attenuation of the bremsstrahlung by the lead. This decrease slows at intermediate fractional thicknesses, until at large fractions - where the aluminum thickness is less than the electron range - a sharp increase in the dose occurs. This increase is due to the fact that for such thin aluminum layers, a substantial number of electrons penetrate into the lead layer which is a much more efficient bremsstrahlung radiator than is aluminum. In the case of $0.2-M e V$ incident electrons, no such increase is observed because even the thinnest aluminum layer considered $\left(0.1 \mathrm{~g} / \mathrm{cm}^{2}\right)$ is sufficient to stop all the electrons.

For a number of cases in which the total mass thickness of the shield is $3 \mathrm{~g} / \mathrm{cm}^{2}$, depth-dose distributions obtained from simple slab calculations were transformed to the spherical geometry. These results are shown as the open circles in figures $2 a$ and $b$. The agreement with the results from the direct calculations is reasonably good (typically 10-20 percent), both in respect to the absolute value of the dose in the three-dimensional geometry and in respect to the relative trends of the curves.

\section{RESULTS FOR SOME REALISTIC INCIDENT ELECTRON SPECTRA}

The foregoing monoenergetic results can be applied to any electron spectrum of interest. Let $F(E)$ be the energy deposited in the water sphere by electrons incident with kinetic energy $E$, per unit incident ellectron fluence, with $F(E)$ in units of $\mathrm{keV} /\left(\right.$ electron $\mathrm{cm}^{-2}$ ) ( see Figs. 2 and $3^{\star}$ ). Let $\phi(E)$ be the full-space $(4 \pi)$ incident electron flux, differential in incident electron kinetic energy $E$, in units of electron keV-1 $\mathrm{cm}^{-2} \mathrm{sec}^{-1}$. Let $M$ be the mass in yrams of the water target sphere $(M=33510 \mathrm{~g})$. Then, for the flux spectrum $\phi(E)$, the absorbed dose $D[\phi(E)]$ in the water sphere, in units of $\mathrm{rads} / \mathrm{sec}$ is yiven by

$$
U[\phi(E)]=\frac{K}{M} \int \phi(E) F(E) d E,
$$

where the constant $K=1.6022 \times 10^{-11} \mathrm{rads} /\left(\mathrm{keV} \mathrm{g}^{-1}\right)$.

We have evaluated Eq. (1) for spectra associated with three space shuttle orbits (inclinations of $28^{\circ}, 57^{\circ}$ and $90^{\circ}$, altitude of $300 \mathrm{~km}$ ), and one geosynchronous orbit ( $0^{\circ}$ inclination, $160^{\circ}$ parking longitude, and $35790 \mathrm{~km}$ altitude). The orbit-averaged spectra are shown in figure 4, and were kindly provided by E. G. Stassinopoulos of NASA/GSFC, based on current radiationenvironment models and orbit-integration codes $[9,10]$. The integral in Eq. (1) was evaluated numerically using Simpson's rule for a fine grid of energies, and using cubic-spline interpolation to obtain values of $\phi(E)$ and $F(E)$ on the energy grid.

\footnotetext{
*Note that Figs. 2 and 3 give the energy deposited per unit incident electron. Therefore, $F(E)$ is obtained by dividing those results by 4 (see, e.g.. Ref. [4]).
} 
The results for each of the orbits considered are given in terms of the average dose rate to the water target sphere as a function of the fraction of the shield mass thickness that is lead. Figure 5 gives the results for a shield with a total mass thickness of $3 \mathrm{~g} / \mathrm{cm}^{2}$, and figure 6 for $5 \mathrm{~g} / \mathrm{cm}^{2}$. There are fairly broad minima in the dose-rate curves which indicate, for each of the total mass thicknesses, those fractions of lead that furnish the maximum shielding. For all the cases considered here, these results indicate an optimal thickness for the aluminum layer of about $1 \mathrm{~g} / \mathrm{cm}^{2}$ (actually from 0.7 to $1.3 \mathrm{~g} / \mathrm{cm}^{2}$ ).

The relative effectiveness of the lead is shown in figure 7 a for the $3-\mathrm{g} / \mathrm{cm}^{2}$ shield, and in figure $7 \mathrm{~b}$ for $5 \mathrm{~g} / \mathrm{cm}^{2}$, which give the dose reduction with respect to an all-aluminum shield, as a function of the thickness of the lead layer. It can be seen that replacing a portion of aluminum by a layer of lead only 1-mm thick can reduce the dose by from 30 to 60 percent, depending on the orbit and on the total mass thickness of the shield. A thicker lead layer can reduce the dose by as much as 75 percent without an increase in the total !nass thickness of the shield.

The results obtained from the transformation of slab results for monoenergetic electrons were too few to be able to integrate numerically for the various incident spectra. However, the integration could be carried out implicitly within a single ZTRAN calculation. This was done for the geosynchronous-orbit spectrum in two cases: a shield of $3-\mathrm{g} / \mathrm{cm}^{2}$ aluminum and a twolayer shield of $1.5 \mathrm{-g} / \mathrm{cm}^{2}$ aluminum followed by $1.5 \mathrm{~g} / \mathrm{cm}^{2}$ lead. The result for $3 \mathrm{~g} / \mathrm{cm}^{2}$ of aluminum is $259 \mathrm{mrad} /$ day, only about 16 percent higher than the dose of $223 \mathrm{mrad} /$ day obtained from the direct calculations. For the two-layer shield, the transformed ZTRAN dose is $84 \mathrm{mrad} /$ day which is 9 percent higher than the $77 \mathrm{mrad} /$ day from the ACCEPT calculations (see fig. $5 \mathrm{c}$ ). The slab results thus predict for this two-layer shield a relative dose reduction of 68 percent, which is in good agreement with the reduction of 65 percent obtained from the direct calculations.

\section{CONCLUSION}

Our calculations demonstrate that the bremsstrahlung dose inside spacecraft can be substantially reduced through the use of graded shields, without an increase in the shield mass. Such a notion is not original [11]. However, the present results, from a state-of-the-art Monte Carlo code which accurately treats the radiation transport processes and the geometry, provide a firm quantitative foundation. These data, in addition to being directly applicable to the configurations considered here, are valuable also as benchmark data against which other more-approximate space-shielding calculations can be checked. Thus, we have found for the class of problems considered here that the use of more-computationally-efficient slab calculations can give results which agree with these direct calculations to within 10-20 percent.

\section{ACKNOWLEDGEMENTS}

One of us (G.B.) wishes to thank the National Bureau of Standards for the hospitality afforded during the course of this work. 


\section{REFERENCES}

[1] G. Barnea, M.J. Berger and S.M. Seltzer, J. Spacecraft and Rockets, in press.

[2] M.J. Berger and S.M. Seltzer, Computer Code Collection CCC-107, Radiation Shielding Information Center, Oak Ridge National Laboratory, Oak Ridge, TN (1968).

[3] M.J. Berger, Methods in Computational Physics, Vol. 1 (Academic Press, New York, 1963) 135.

[4] S.M. Seltzer, IEEE Trans. Nucl. Sci. NS-26, 21 (1979).

[5] S.M. Seltzer, National Bureau of Standards Technical Note 1116 (1980).

[6] J.A. Halbleib, Sandia National Laboratories Report SAND 79-0415 (1979).

[7] S.M. Seltzer and M.J. Berger, National Bureau of Standards Report NBSIR 84-2931 (1984).

[8] S.M. Seltzer, IEEE Conf. on Nuclear and Space Radiation Effects, Providence, RI (1986); submitted to IEEE Trans. Nucl. Sci. (1986).

[9] E.G. Stassinopoulos, J. of Spacecraft and Rockets, 17, 145 (1980).

[10] E.G. Stassinopoulos and J.M. Barth, to be submitted to J. of Spacecraft and Rockets (1986).

[11] See, e.g., M.L. Rossi and M.C. Stauber, IEEE Trans Nucl. Sci. NS-24 (1977) 2248. 
Table 1. Dependence of the energy deposited in the water target sphere on the shape and dimensions of the aluminum shield. The results pertain to an isotropic flux of $2-\mathrm{MeV}$ electrons incident on either spherical or cylindrical aluminum shells $1 \mathrm{~cm}$ thick, with the $40-\mathrm{cm}$ diameter water target sphere located at the center of the shell. The directly-calculated results were obtained with the ACCEPT code; the slab results, converted to apply approximately to the threedimensional configuration, were obtained with the ZTRAN code.

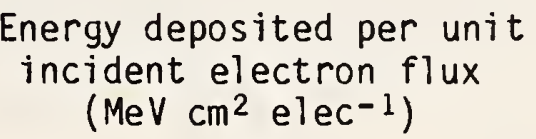

\begin{tabular}{|c|c|c|c|}
\hline Snield & $\begin{array}{l}\text { Shape and } \\
\text { Outside Dimension(s) }\end{array}$ & ACCEPT & $\begin{array}{l}\text { From } \\
\text { ZTRAN }\end{array}$ \\
\hline $\begin{array}{l}1 \\
2 \\
3 \\
4 \\
5\end{array}$ & $\begin{array}{l}\text { sphere, } 42-\mathrm{cm} \text { diam. } \\
\text { sphere, } 100-\mathrm{cm} \text { diam. } \\
\text { sphere, } 200-\mathrm{cm} \text { diam. } \\
\text { sphere, } 300-\mathrm{cm} \text { diam. } \\
\text { sphere, } 400-\mathrm{cm} \text { diam. }\end{array}$ & $\begin{array}{c}10.1 \\
9.90 \\
9.75 \\
9.68 \\
9.53\end{array}$ & $\begin{array}{l}11.7 \\
11.6 \\
11.4 \\
11.4 \\
11.3\end{array}$ \\
\hline 6 & $\begin{aligned} \text { cylinder }^{\mathrm{a}}, & 126.5-\mathrm{cm} \text { diam. } \\
& 253.0-\mathrm{cm} \text { height }\end{aligned}$ & 9.83 & 11.2 \\
\hline 7 & $\begin{array}{rl}c y l i n d e r & b \\
& 253-c m \text { diam. } \\
& 506-c m \text { height }\end{array}$ & 9.25 & 11.4 \\
\hline
\end{tabular}


Table 2. Dependence of the energy deposited in the $40-\mathrm{cm}$ diameter water target sphere on the position of the target within the shield. The results were calculated directly with the ACCEPT code and pertain to an isotropic flux of 2-MeV electrons incident on either a spherical or cylindrical aluminum shell $1 \mathrm{~cm}$ thick.

A. Spherical shel1: outside diameter $300 \mathrm{~cm}$

Distance from center of she 11
to center of target sphere

0

$125 \mathrm{~cm}$
Energy deposited per unit incident electron flux

$\left(\mathrm{MeV} \mathrm{cm}^{2} \mathrm{elec}^{-1}\right.$ )

9.68

10.8

B. Cylindrical shell: outside diameter $253 \mathrm{~cm}$, height $506 \mathrm{~cm}$

Distance along cylinder axis

from center of shell to

center of target sphere

0

$100 \mathrm{~cm}$

$232 \mathrm{~cm}$

\section{Energy deposited per unit incident electron flux \\ (MeV $\mathrm{cm}^{2} \mathrm{elec}^{-1}$ )}

\subsection{5}

9.45

10.3 


\section{FIGURE CAPTIONS}

Fig. 1. Schematization of spacecraft for shielding calculations.

Fig. 2. Average energy deposited in the central water sphere due to an isotropic flux of monoenergetic electrons incident on an outer shield of mass thickness $3 \mathrm{~g} / \mathrm{cm}^{2}$. The results are given as a function of the fractional mass thickness of the lead layer in the shield, and are normalized to one incident electron. The solid points, fit by the solid curves, represent results from the ACCEPT code. The open circles represent slab results from the ZTRAN code, converted to apply approximately to the three-dimensional configuration. The arrows indicate the fractional thicknesses which correspond to the continuous-slowing-down-approximation values of the electron range in a Tuminum.

a. Incident electron energies: 0.2 and $0.5 \mathrm{MeV}$.

b. Incident electron energies: $1,2,3,4,5$, and $6 \mathrm{MeV}$.

Fig. 3. Average energy deposited in the central water sphere due to an isotropic flux of monoeneryetic electrons incident on an outer shield of mass thickness $5 \mathrm{~g} / \mathrm{cm}^{2}$. The results are given as a function of the fractional mass thickness of the lead layer in the shield, and are normalized to one incident electron. The points (solid and open), fit by the solid curves, represent results from the ACCEPT code. The arrows indicate the fractional thicknesses which correspond to the continuous-slowing-down-approximation values of the electron range in a luminum.

Fig. 4. Average differential flux of incident electrons for selected shuttle and geosynchronous orbits. Orbit parameters are indicated in the figure.

Fig. 5. Average dose rates in the central water sphere due to various spectra of electrons incident on an outer shield of mass thickness $3 \mathrm{~g} / \mathrm{cm}^{2}$. The results, obtained with the ACCEPT code, are given as a function of the fractional mass thickness of the lead layer in the shield.

a. Shuttle orbits: $300 \mathrm{~km}$ altitude and inclinations of $57^{\circ}$ and $90^{\circ}$.

b. Shuttle orbit: $300 \mathrm{~km}$ altitude and $28^{\circ}$ inclination.

c. Geosynchronous orbit: $35790 \mathrm{~km}$ altitude, $0^{\circ}$ inclination, and $160^{\circ} \mathrm{W}$ parking longitude. The single open circle represents slab results from the ZTRAN code, converted to apply approximately to the three-dimensional configuration.

Fig. 6. Average dose rates in the central water sphere due to various spectra of electrons incident on an outer shield of mass thickness $5 \mathrm{~g} / \mathrm{cm}^{2}$. The results, obtained with the ACCEPT code, are given as a function of the fractional mass thickness of the lead layer in the shield.

a. Shuttle orbits: $300 \mathrm{~km}$ altitude and inclinations of $57^{\circ}$ and $90^{\circ}$.

b. Shuttle orbit: $300 \mathrm{~km}$ altitude and $28^{\circ}$ inclination.

c. Geosynchronous orbit: $35790 \mathrm{~km}$ altitude, $0^{\circ}$ inclination, and $160^{\circ} \mathrm{W}$ parking longitude. 
Fig. 7. Percent dose reduction relative to the case of an all-aluminum shield. The reduction of the dose to the central water sphere is given as a function of the mass thickness of the lead layer in the aluminum/lead shield whose total mass thickness is kept constant.

Curves A - Shuttle orbit: $300 \mathrm{~km}$ altitude and $57^{\circ}$ inclination.

Curves B - Shuttle orbit: $300 \mathrm{~km}$ altitude and $90^{\circ}$ inclination.

Curves C - Shuttle orbit: $300 \mathrm{~km}$ altitude and $28^{\circ}$ inclination.

Curves D - Geosynchronous orbit: $35790 \mathrm{~km}$ altitude, $0^{\circ}$ inclination, and $160^{\circ} \mathrm{W}$ parking longitude.

a. Total mass thickness of the shield is $3 \mathrm{~g} / \mathrm{cm}^{2}$.

b. Total mass thickness of the shield is $5 \mathrm{~g} / \mathrm{cm}^{2}$. 


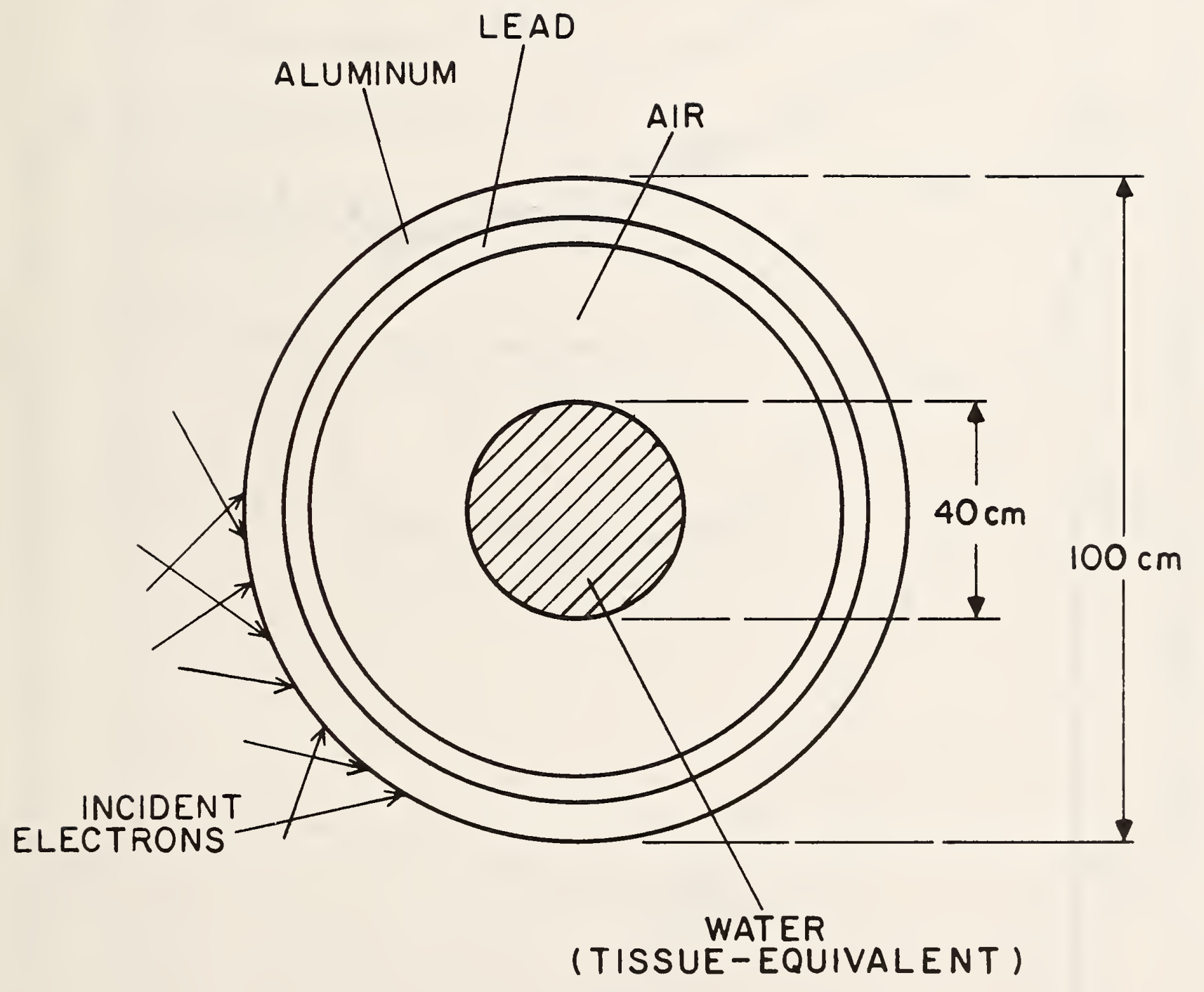

Fig. 1 


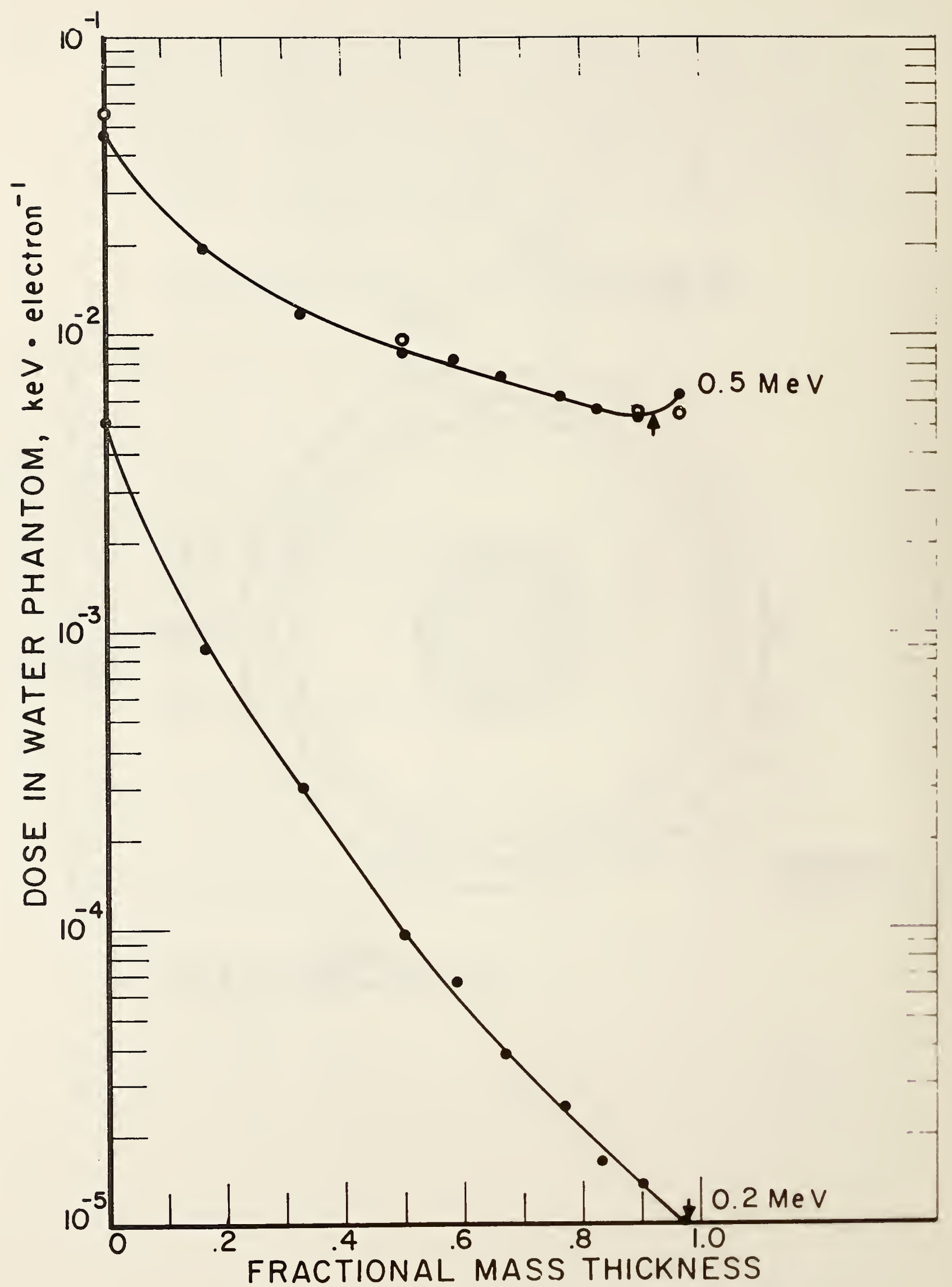

Fig. 2a 


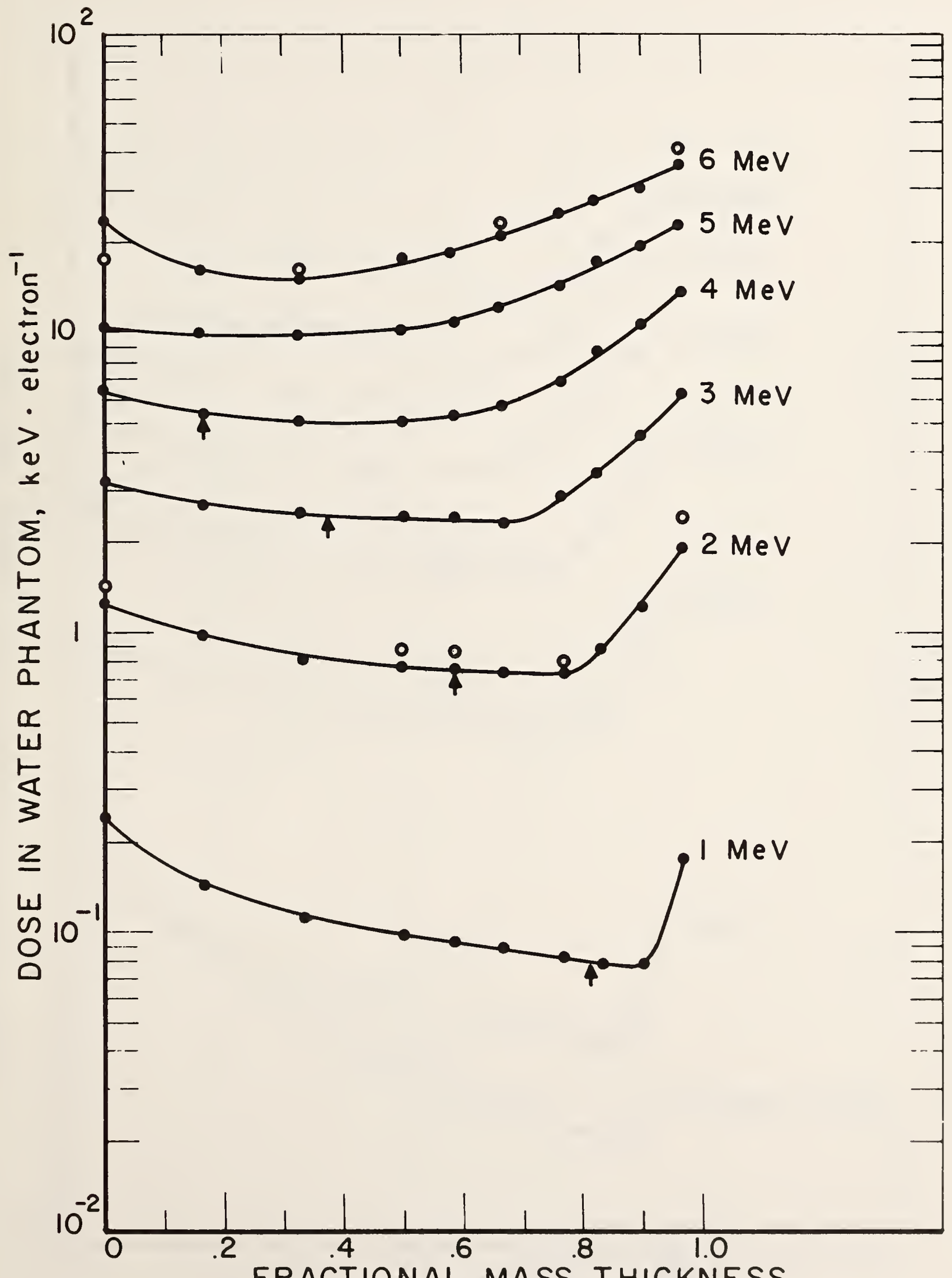

FRACTIONAL MASS THICKNESS

Fig. $2 b$ 



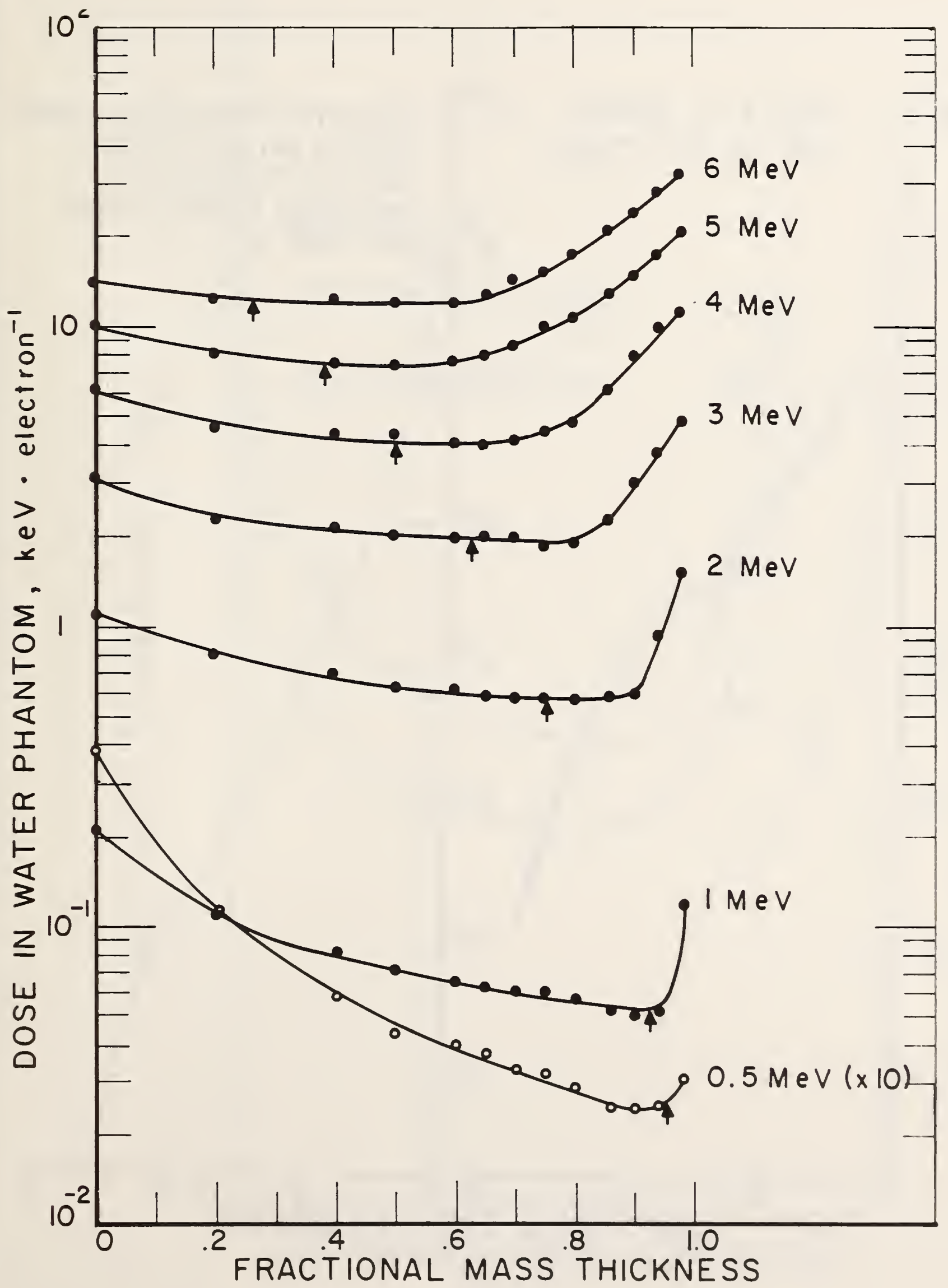

Fig. 3 


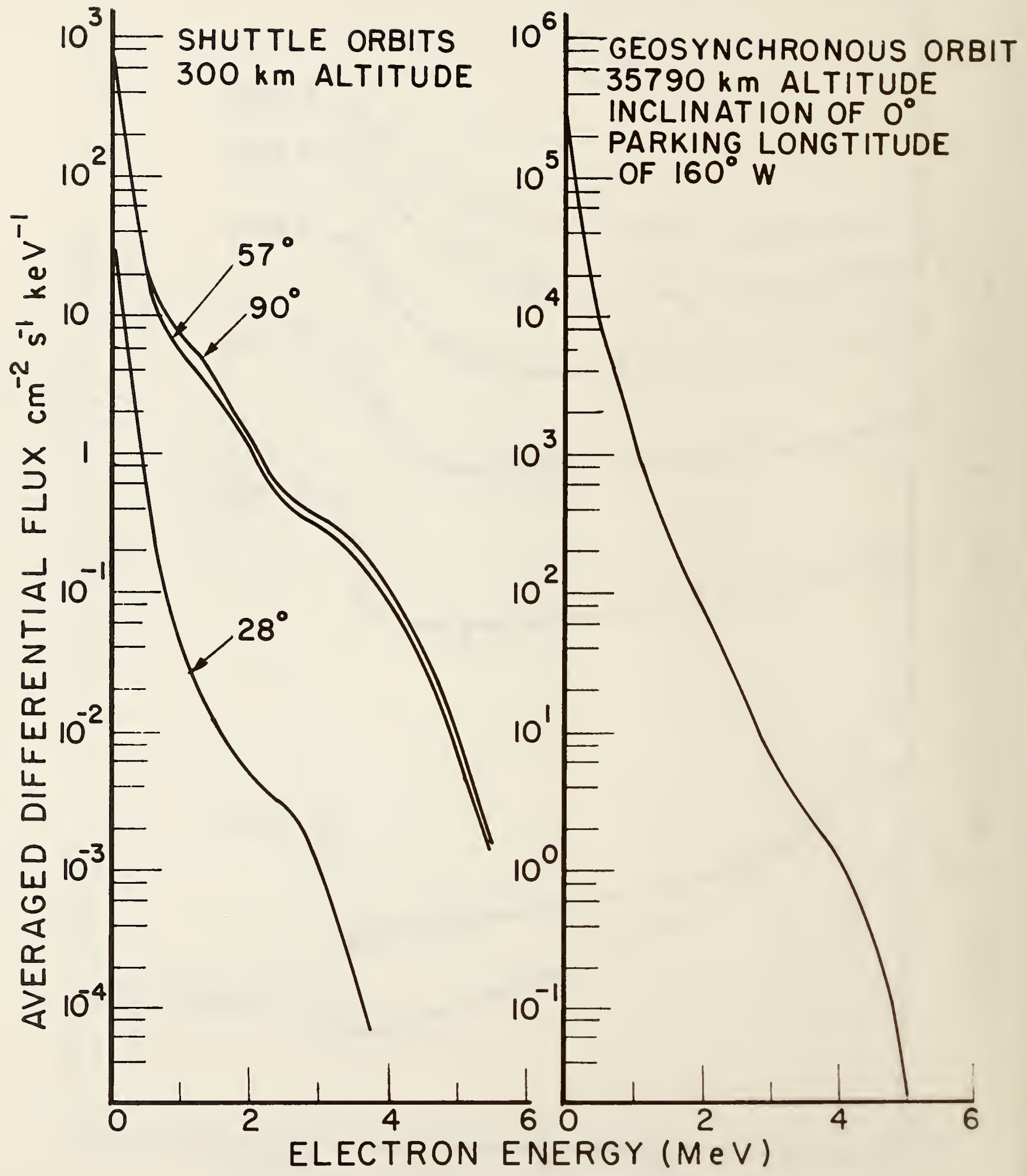

Fig. 4 


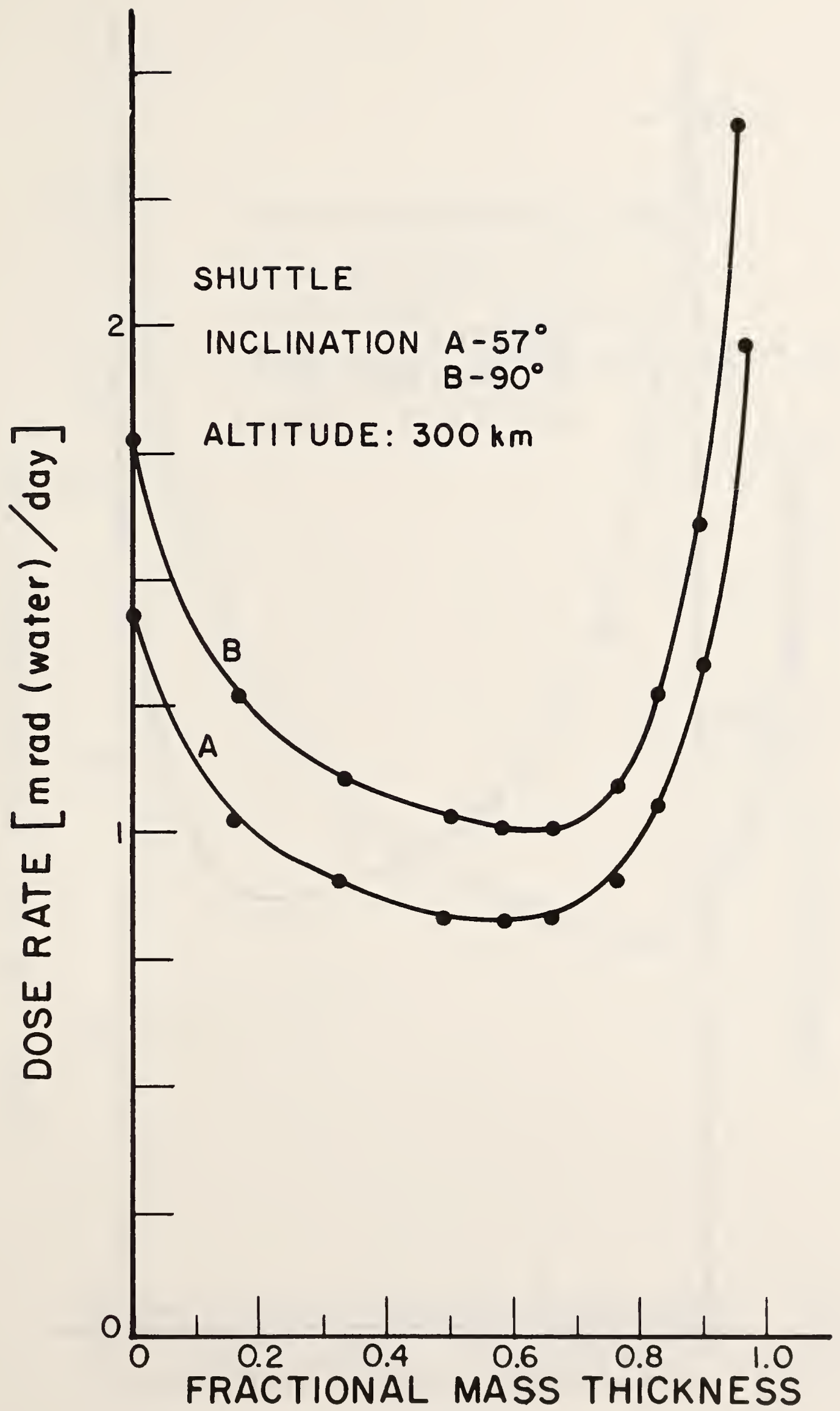

Fig. $5 \mathrm{a}$ 


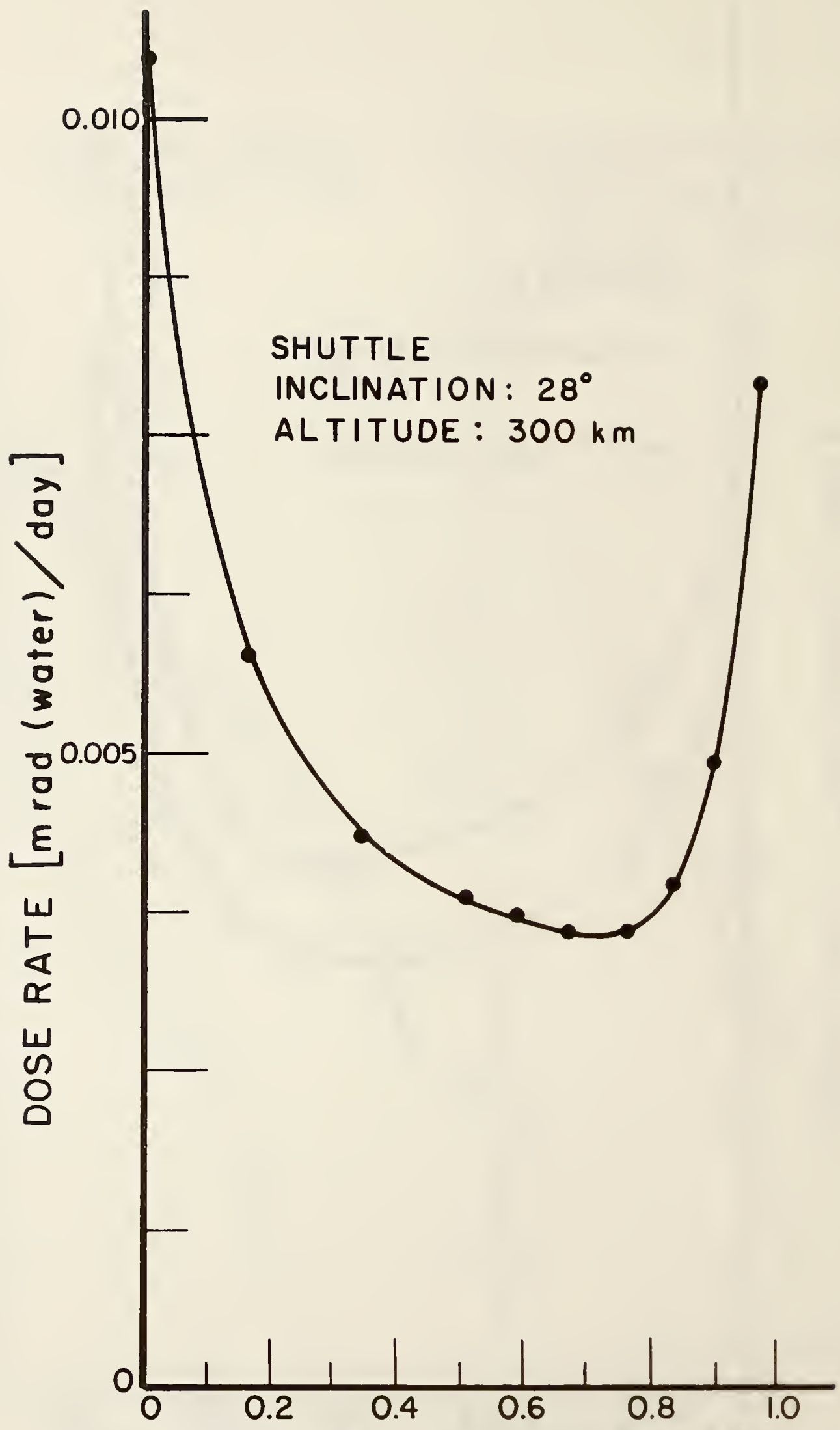

FRACTIONAL MASS THICKNESS

Fig. 5b 


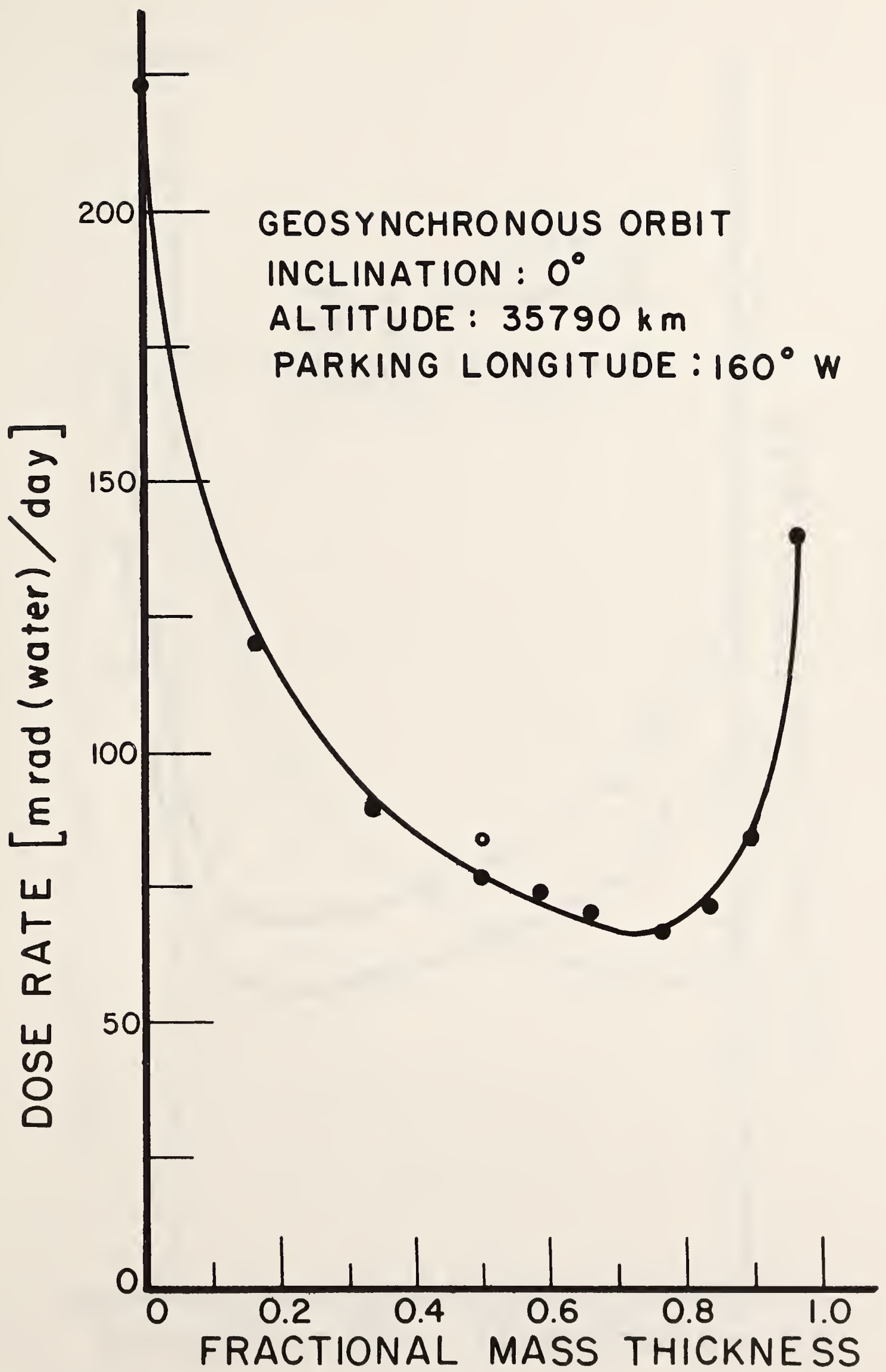

Fig. $5 \mathrm{C}$ 


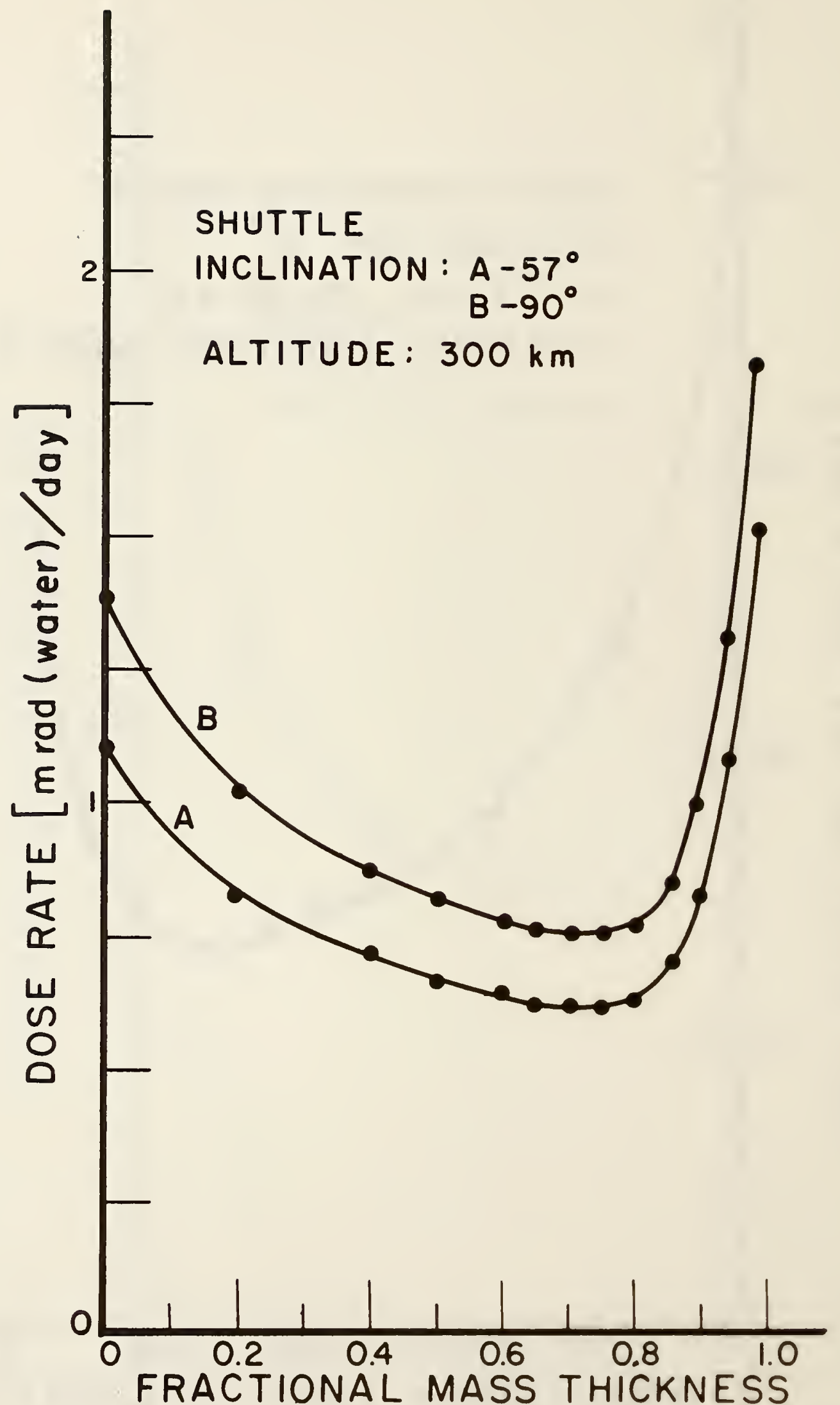

Fig. $6 a$ 


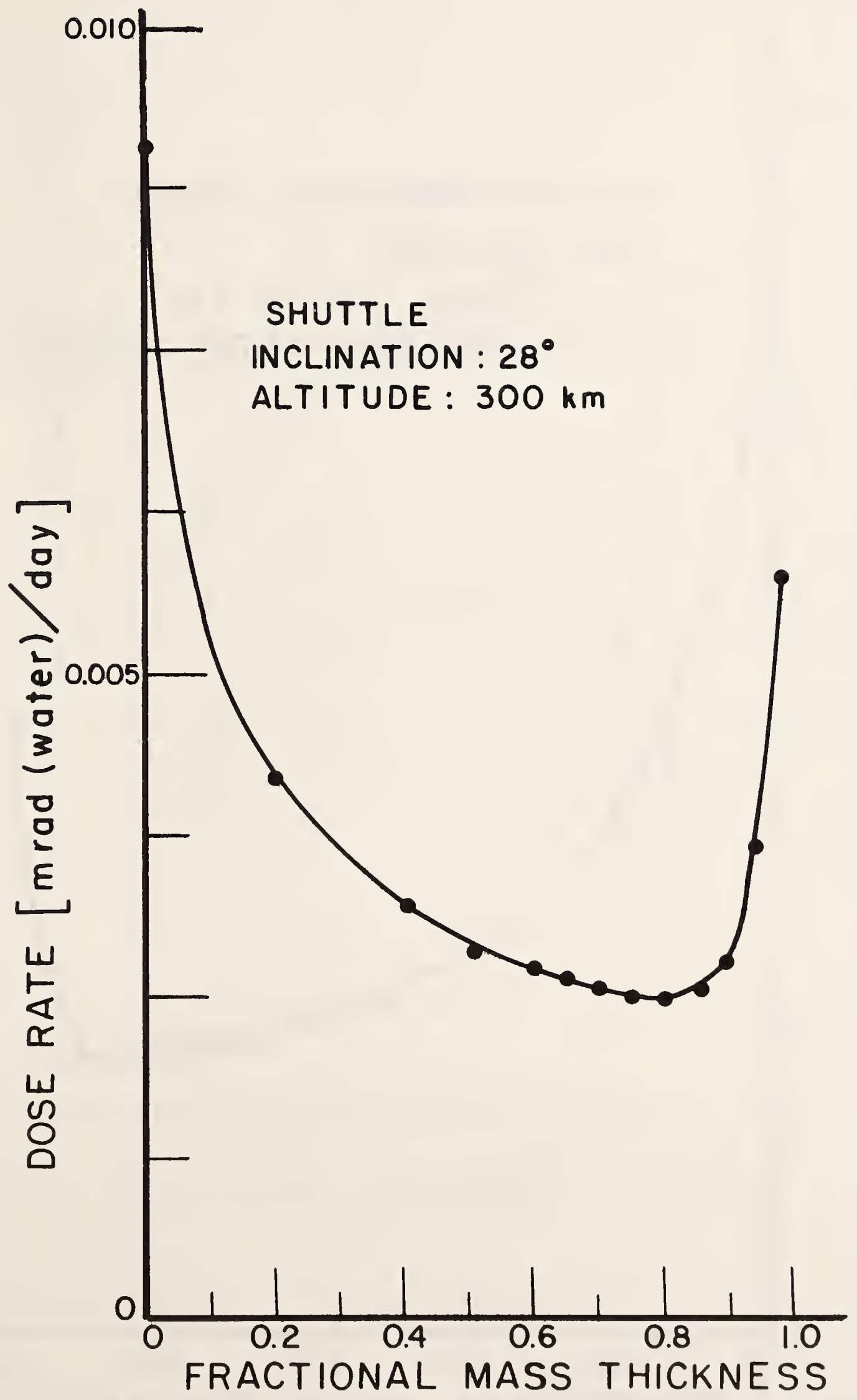

Fig. 6b 


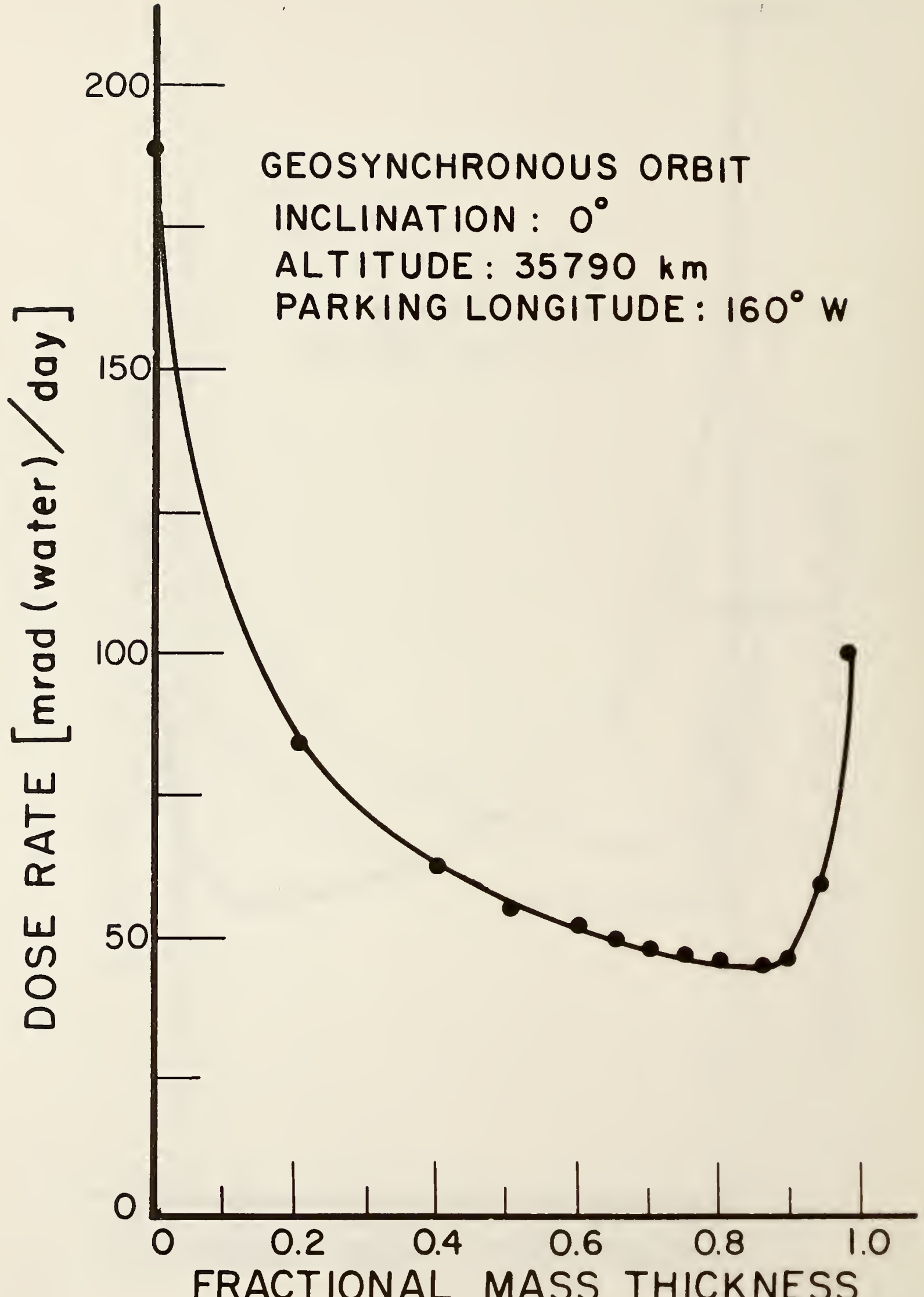

Fig. 6c 


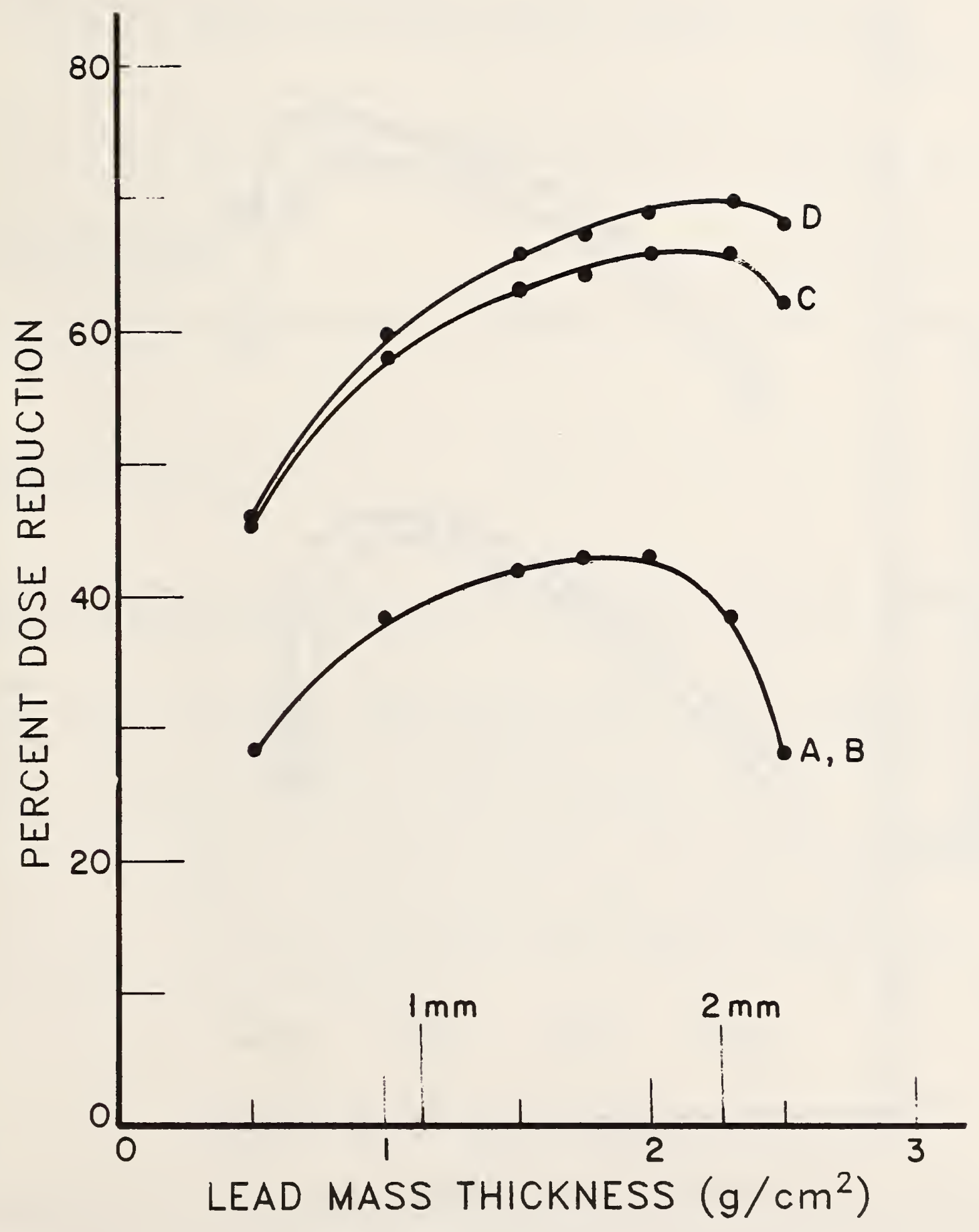

Fig. $7 a$ 


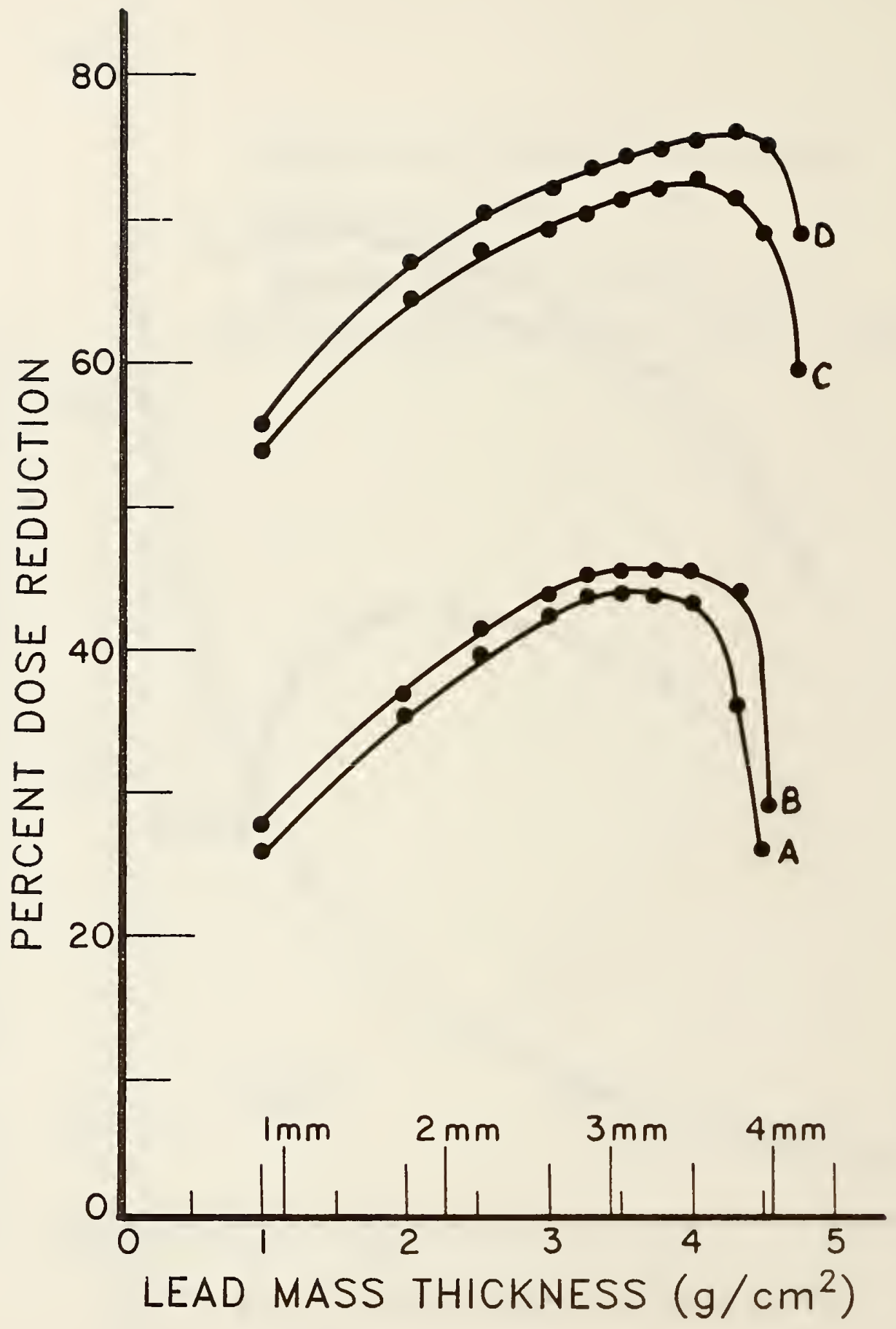

Fig. 7b 


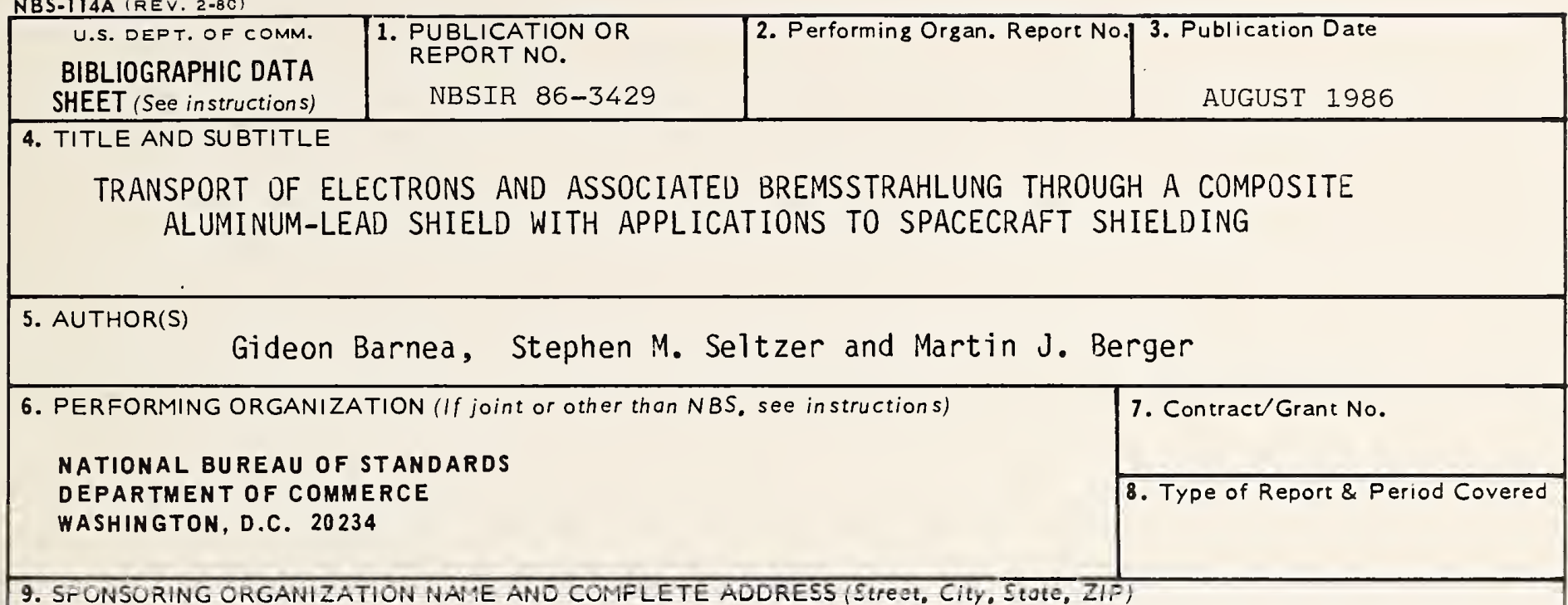

9. SFONSORING ORGANHZATION NAME ANO COMFLETE ADDRESS (Street, CIty, Stote, ZIP)

10. SUPPLEMENTARY NOTES

$\square$ Document describes a computer program; SF-185, FIPS Software Summary, is attached.

11. ABSTRACT (A 200-word or less factual summary of most significant information. If document includes a significant bibliography or literature survey. mention it here)

Monte Carlo calculations have been made of the stopping of electrons and the penetration of secondary bremsstrahlung through layered aluminum-lead spacecraft walls. The results are presented in terms of the resultant radiation dose to objects inside. Dose values for monoenergetic incident electrons are given as a function of the aluminum/lead thickness ratio. These data, integrated over a few typical Earth-orbit electron spectra, demonstrate the substantial reduction in radiation dose that can be achieved by replacing a portion of an aluminum shield with an inner layer of lead. The main results were obtained by applying a complex-geometry code to spherical-shell configurations. It was found that these results could be reasonably well approximated by an alternative and more economical approach, involving the use of slab-geometry transport results.

12. KEY WORDS (Six to twelve entries: alphabetical order; copitalize only proper names; and seporate key words by semicolons) absorbed dose; bremsstrahlung; composite shield; electrons; Monte Carlo calculation; space shielding;

13. AVAILABILITY

X Unlimited

$\square$ For Official Distribution. Do Not Release to NTIS

- Order From Superintendent of Documents, U.S. Government Printing Office, Washıngton, D.C. 20402.

$[X]$ Order From National Technical Information Service (NTIS), Springfield, VA. 22161
14. NO. OF PRINTED PAGES

27

15. Price

$\$ 9.95$ 


